particularly evident among patients with complex lesions. Efforts should be undertaken to reduce the incidence of stroke, however, which remains higher in patients undergoing CABG. Aortic "no touch" off-pump CABG has been recently proposed as a means of minimizing the risk of perioperative stroke. The rate of off-pump surgery varied among the trials included, ranging from $1.8 \%{ }^{5}$ to $63.8 \%{ }^{4}$ A trend toward an increased rate of stroke was found among patients undergoing CABG regardless of the rate of off-pump surgery. No data were available on manipulation of the ascending aorta or the use of epiaortic scanning, however, so whether off-pump surgery would truly be beneficial cannot be evaluated, and further studies are needed.

Despite these limitations, this meta-analysis demonstrates a significant reduction in repeated revascularization with $\mathrm{CABG}$, which outweighs its detrimental increase in stroke rate. Only first-generation DESs were used in all the included RCTs, however, limiting our ability to draw conclusions for second-generation devices.

\section{References}

1. Athappan G, Patvardhan E, Tuzcu ME, Ellis S, Whitlow P, Kapadia SR. Left main coronary artery stenosis: a meta-analysis of drug-eluting stents versus coronary artery bypass grafting. JACC Cardiovasc Interv. 2013;6:1219-30.

2. Morice MC, Serruys PW, Kappetein AP, Feldman TE, Ståhle E, Colombo A, et al. Five-year outcomes in patients with left main disease treated with either percutaneous coronary intervention or coronary artery bypass grafting in the SYNTAX Trial. Circulation. 2014;129:2388-94.

3. Boudriot E, Thiele H, Walther T, Liebetrau C, Boeckstegers P, Pohl T, et al. Randomized comparison of percutaneous coronary intervention with sirolimuseluting stents versus coronary artery bypass grafting in unprotected left main stem stenosis. J Am Coll Cardiol. 2011;57:538-45.

4. Park SJ, Kim YH, Park DW, Yun SC, Ahn JM, Song HG, et al. Randomized trial of stents versus bypass surgery for left main coronary artery disease. $N$ Engl J Med. 2011;364:1718-27.

5. Buszman PE, Kiesz SR, Bochenek A, Peszek-Przybyla E, Szkrobka I, Debinski M, et al. Acute and late outcomes of unprotected left main stenting in comparison with surgical revascularization. J Am Coll Cardiol. 2008;51: $538-45$.

\title{
Single-center experience with a minimally invasive apicoaxillary external ventricular assist device
}

\author{
Elissa Landes, MD, Yoshifumi Naka, MD, PhD, Koji Takeda, MD, PhD, and Hiroo Takayama, MD, PhD, \\ New York, NY
}

Mechanical circulatory support (MCS) devices have become more popular in the treatment of cardiogenic shock (CS). Options for emergency support include venoarterial extracorporeal membrane oxygenation, percutaneous ventricular assist devices (VADs), and surgical VADs. Among MCS devices, surgical VADs have the advantage of providing sufficient circulatory support ${ }^{1}$; however, the standard technique requires implantation through a median sternotomy. ${ }^{2}$

Previously, we described a unique configuration of the CentriMag (Thoratec Corporation, Pleasanton, Calif) left VAD (LVAD) that allowed rapid off-pump placement without performing a sternotomy. ${ }^{3}$ Here we present a series

\footnotetext{
From the Department of Surgery, Columbia University Medical Center, New York, NY.

Disclosures: Yoshifumi Naka reports consulting fees from Thoratec. All other authors have nothing to disclose with regard to commercial support.

Received for publication April 18, 2014; revisions received June 29, 2014; accepted for publication July 14, 2014; available ahead of print Aug 28, 2014.

Address for reprints: Hiroo Takayama, MD, PhD, 177 Fort Washington Ave, New York, NY 10032 (E-mail: ht2225@cumc.columbia.edu).

J Thorac Cardiovasc Surg 2014;148:2432-4

$0022-5223 / \$ 36.00$

Copyright (C) 2014 by The American Association for Thoracic Surgery

http://dx.doi.org/10.1016/j.jtcvs.2014.07.086
}

of cases of patients who received this external apicoaxillary LVAD (AA-LVAD) as a bridge to decision.

\section{MATERIALS AND METHODS}

Our institutional review board approved this study. Between January 2007 and December 2013, a series of 198 patients underwent CentriMag VAD insertion for CS at our institution. The cases of 7 patients who received AA-LVADs were reviewed.

\section{Indications}

Indications for AA-LVAD placement include patients in CS who require VAD support but do not meet criteria for durable MCS device implantation at the time of evaluation. Our default strategy for device therapy in CS is to insert a short-term biventricular VAD, so this technique is reserved for those who can succeed with isolated LVAD support. Patients with CS who have peripheral vascular disease that precludes the use of a percutaneous MCS may also be considered for this support. Patients are excluded if there are mechanical obstacles to cannulation of their axillary artery or left ventricular apex.

\section{Technique}

The details of AA-LVAD implantation are described elsewhere. Briefly, after intubation, the axillary artery (right or left) is exposed through a small infraclavicular incision, and the left ventricular apex is exposed through a left anterior thoracotomy. Heparin of 5 to 10,000 units is given. An 8-mm Dacron polyester fabric graft is sewn end to side to the axillary artery, and the arterial cannula (24F EOPA; Medtronic, Inc, 
TABLE 1. Patient characteristics and operative data

\begin{tabular}{|c|c|c|c|c|c|c|c|c|c|c|}
\hline & & & & & haracteri & tics & & & Operative d & \\
\hline & Age (y) & Sex & $\begin{array}{c}\text { Sternotomy } \\
\text { (No.) }\end{array}$ & MCS & CVVH & Etiology of heart failure & $\begin{array}{c}\text { INTERMACS } \\
\text { level }\end{array}$ & LV cannula & EBL $(\mathbf{m L})$ & PRBCs (units) \\
\hline 1 & 50 & M & 2 & None & No & NIDCM & 1 & $40 \mathrm{~F}$ & - & 0 \\
\hline 2 & 52 & $\mathrm{~F}$ & 1 & None & No & ICM & 1 & $34 \mathrm{~F}$ & 300 & 2 \\
\hline 3 & 62 & M & 2 & ECMO & Yes & ICM & 1 & $36 \mathrm{~F}$ & 200 & 1 \\
\hline 4 & 28 & $\mathrm{~F}$ & 3 & None & No & Rheumatic disease, ICM & 1 & $24 \mathrm{~F}$ & 300 & 4 \\
\hline 5 & 53 & M & 2 & ECMO & No & Rheumatic disease & 1 & $32 \mathrm{~F}$ & 25 & 0 \\
\hline 6 & 68 & M & 1 & IABP & No & ICM & 1 & $36 \mathrm{~F}$ & 50 & 0 \\
\hline 7 & 65 & M & 1 & IABP & No & ICM & 1 & $36 \mathrm{~F}$ & 50 & 0 \\
\hline
\end{tabular}

MCS, Mechanical circulatory support; $C V V H$, continuous venovenous hemofiltration; INTERMACS, Interagency Registry for Mechanically Assisted Circulatory Support; $L V$, left ventricle; $E B L$, estimated blood loss; PRBCs, packed red blood cells; NIDCM, nonischemic dilated cardiomyopathy (secondary to congenital bicuspid aortic valve); $I C M$, ischemic cardiomyopathy; ECMO, extracorporeal membrane oxygenation; IABP, intra-aortic balloon pump.

Minneapolis, Minn) is inserted into the graft. Double purse-string sutures buttressed with felt pledgets are placed at the left ventricular apex, and the inflow cannula (Table 2) is inserted 2.5 to $3 \mathrm{~cm}$ into the left ventricle through a stab wound. The cannulas are then connected to a CentriMag circuit. No cardiopulmonary bypass support is required. Heparin is started (goal of a partial thromboplastin time of 60-80 seconds) when chest tube output is minimal. Blood pressure is monitored through an arterial line in the contralateral upper extremity when possible. If a femoral line is required, it is revised before the patient reaches the stage of ambulation. The patients participate in ambulatory rehabilitation when feasible and, when their general condition is stable, undergo next step evaluation for explantation, device exchange, or heart transplantation.

\section{RESULTS}

Seven patients received AA-LVADs through the right axillary artery. The average $( \pm$ SD) age was $54 \pm 12$ years (range, 28-68 years). All were in CS as a result of acute decompensated heart failure, and all had had previous sternotomies. At the time of implantation, 4 patients were receiving MCS with either an intra-aortic balloon pump (IABP) or venoarterial extracorporeal membrane oxygenation (Table 1). The IABP was removed within 24 hours after the operation. Among the 3 patients who were not receiving MCS, IABP was contraindicated in 1 case because of a type $\mathrm{B}$ aortic dissection, and attempts at IABP insertion failed in the other 2 cases because of incompatible vasculature.
All insertions were done off pump with minimal blood loss (Table 1). The average flow during the first 72 hours was $4 \pm 0.9 \mathrm{~L} / \mathrm{min}$. Five patients $(71 \%)$ were weaned from mechanical ventilation within 72 hours (3 within 24 hours, 2 within 48 hours). Four patients participated in ambulatory rehabilitation, and 2 were able to be out of bed to a chair. Four patients $(57 \%)$ were free of any major complications. Two patients had infections develop. Three had neurologic complications, although only 1 of those was major (Table 2). Two patients had bleeding complications requiring reoperation. One patient underwent a colectomy for colon cancer. One patient had clinically observed hyperperfusion of the right upper extremity but did not require revision of the arterial outflow tract. There were no other adverse events associated with the axillary cannulation.

Five patients $(71 \%)$ survived to the next step: 1 to transplant and 4 to durable LVAD implantation (2 as destination therapy and 2 as bridge to transplant). Two patients died of multisystem organ failure (Table 2).

\section{DISCUSSION}

Although recent studies have shown the benefit of early and aggressive use of MCS devices in patients with critical heart failure, ${ }^{4}$ durable MCS devices are known to result in both poor operative mortality and poor long-term outcomes in this same population..$^{5}$ Percutaneous devices are an

TABLE 2. Outcomes

\begin{tabular}{|c|c|c|c|c|c|c|c|}
\hline & Duration (d) & $\begin{array}{c}\text { Pressor support } \\
\text { at } 72 \mathrm{~h} \text { (No. of drips) }\end{array}$ & CVA & Infection & Reoperation & Survival to discharge & Primary outcome \\
\hline 1 & 48 & 1 & SAH & PNA & Bleeding from axilla & Yes & $\mathrm{OHT}$ \\
\hline 2 & 14 & 1 & None & None & None & Yes & HMII BTT \\
\hline 3 & 17 & 4 & VBI & None & None & No & Death \\
\hline 4 & 56 & 1 & $\mathrm{SAH}$ & PNA, Clostridium difficile & Hemothorax $\times 2$ & No & Death \\
\hline 5 & 7 & 3 & None & None & None & Yes & HMII DT \\
\hline 6 & 22 & 0 & None & None & Colectomy & Yes & HMII BTT \\
\hline 7 & 20 & 1 & None & None & None & Yes & HMII DT \\
\hline
\end{tabular}

CVA, Cerebrovascular accident; SAH, subarachnoid hemorrhage; PNA, pneumonia; OHT, orthotopic heart transplant; HMII, Heartmate II (Thoratec Corp, Pleasanton, Calif); $B T T$, bridge to transplant; $V B I$, vertebrobasilar insufficiency; $D T$, destination therapy. 
appealing option, yet they may be too limited in flow and durability. ${ }^{2}$ The AA-LVAD combines the benefit of a relatively quick insertion with sufficient circulatory support for restoration of end-organ function ${ }^{4}$ and avoids the hazards of resternotomy and invasive surgery.

\section{References}

1. Werdan K, Gielen S, Ebelt H, Hochman JS. Mechanical circulatory support in cardiogenic shock. Eur Heart J. 2014;35:156-67.
2. Ziemba EA, John R. Mechanical circulatory support for bridge to decision: which device and when to decide. J Card Surg. 2010;25:425-33.

3. Takayama H, Naka Y, Jorde UP, Stewart AS. Less invasive left ventricular assist device placement for difficult resternotomy. J Thorac Cardiovasc Surg. 2010;140: 932-3

4. Akay MH, Gregoric ID, Radovancevic R, Cohn WE, Frazier OH. Timely use of a CentriMag heart assist device improves survival in postcardiotomy cardiogenic shock. J Card Surg. 2011;26:548-52.

5. Rao V, Oz MC, Flannery MA, Catanese KA, Argenziano M, Naka Y. Revised screening scale to predict survival after insertion of a left ventricular assist device. J Thorac Cardiovasc Surg. 2003;125:855-62.

\title{
Are preoperative B-type natriuretic peptide levels associated with outcome after pulmonary artery banding and the double switch operation in patients with congenitally corrected transposition of the great arteries: A pilot study
}

\author{
Danton S. Char, MD, ${ }^{a}$ Stephen C. Shiboski, PhD, ${ }^{b}$ Frank L. Hanley, MD,${ }^{c}$ and Jeffrey R. Fineman, MD, ${ }^{d}$ \\ Stanford and San Francisco, Calif
}

Pulmonary artery banding (PAB) for ventricular training followed by the double switch operation (DSO) is an attractive surgical option for suitable patients with congenitally corrected transposition of the great arteries (ccTGA). After repair, the systemic circulation is supported by the morphologic left ventricle (LV). Adoption of DSO was driven by the poor natural history of the systemic right ventricle (RV) and successful outcomes with DSO have been reported since the mid-1990s. ${ }^{1}$ Although mortality after these operations is low with careful patient selection, the accurate prediction of adverse postoperative outcomes is difficult, and there remains an unpredictable risk of morbidity, takedown or reoperation. ${ }^{2}$

Recent studies have demonstrated that perioperative changes in B-type natriuretic peptide (BNP) levels may

\footnotetext{
From the Division of Pediatric Anesthesia, ${ }^{a}$ Department of Anesthesiology, Stanford University School of Medicine, Stanford, Calif; Department of Epidemiology and Biostatistics, ${ }^{\text {b }}$ University of California, San Francisco, Calif; Pediatric Heart Center, ${ }^{c}$ Lucile Packard Children's Hospital, Stanford University School of Medicine, Stanford, Calif; and Division of Pediatric Critical Care Medicine, ${ }^{d}$ Department of Pediatrics, University of California, San Francisco, Calif.

This study was made possible by funding from the Pediatric Heart Center Research Program, Lucile Packard Foundation for Children's Health, Stanford CTSA (grant number UL1 RR025744).

Disclosures: Authors have nothing to disclose with regard to commercial support.

Received for publication April 17, 2014; revisions received June 17, 2014; accepted for publication July 7, 2014; available ahead of print Aug 16, 2014.

Address for reprints: Danton S. Char, MD, Department of Anesthesiology, H3580, Stanford University Medical Center, 300 Pasteur Drive, Stanford, CA 94305 (E-mail: dchar@stanford.edu).

J Thorac Cardiovasc Surg 2014;148:2434-6

$0022-5223 / \$ 36.00$

Copyright (c) 2014 by The American Association for Thoracic Surgery

http://dx.doi.org/10.1016/j.jtcvs.2014.07.003
}

predict postoperative morbidity and mortality after surgery for the repair or palliation of congenital cardiac defects. However, the potential usefulness of preoperative BNP levels as predictors of postoperative outcomes in patients undergoing repair for ccTGA has not been investigated.

This pilot study hypothesized that preoperative BNP levels could be associated with unexpected outcomes after PAB and DSO in patients otherwise deemed to be suitable operative candidates on the basis of standard preoperative clinical, echocardiographic, and hemodynamic assessments.

\section{MATERIALS AND METHODS \\ Design and Participants}

A pilot prospective cohort study was undertaken at Lucile Packard Children's Hospital Heart Center from November 2011 to November 2013. Eligible participants included all patients with ccTGA undergoing either PAB or DSO. Management followed standard institutional practices. Informed consent from the patients or their guardians was obtained before enrollment. The Stanford University Medical Center Institutional Review Board approved the study (IRB 22458).

Blood samples were obtained from a venous or arterial catheter less than 24 hours preoperatively and were assayed using a commercially available fluorescence immunoassay (Triage Meter Plus; Biosite Diagnostic, San Diego, Calif).

\section{Outcome}

The end point was a composite of adverse outcomes including death, cardiac arrest, need for extracorporeal cardiopulmonary life support or emergency reoperation.

\section{Analysis}

The 2-sided Fisher exact test was used to evaluate the association between increased BNP level $(>300 \mathrm{pg} / \mathrm{mL})$ and the binary composite 